\title{
POLÍTICAS DE DESENVOLVIMENTO PRODUTIVO, TECNOLÓGICO E DE INOVAÇÃO: A PERSPECTIVA DA SEGURANÇA NACIONAL
}

\author{
Rafael Leão' \\ Luis Felipe Giesteira
}

\section{SINOPSE}

O risco de a atual crise sanitária evoluir, no Brasil, para patamares dramáticos relaciona-se, em parte, à sua fragilidade tecnológica e produtiva. $\mathrm{O}$ aumento dessas fragilidades em diversos dos nossos segmentos econômicos compromete sobremaneira a capacidade do Brasil em responder a crises como a atual. O presente texto sugere que a construção de capacidade produtiva, tecnológica e inovadora orientadas por missóes e demandas de Estado aumentaria a capacidade do país em responder mais efetivamente a outras crises que possam nos acometer.

Palavras-chave: pandemia; coronavírus; Covid-19; política de desenvolvimento produtivo, tecnológico e de inovação; segurança nacional.

\section{INTRODUÇÃO}

O Brasil está enfrentando um dos maiores desafios de sua história recente. Nossa população, nossa economia e nossos sistemas de bem-estar serão colocados à prova diante da pandemia da Covid-19.

Autoridades sanitárias têm relatado carência de testes, insumos e equipamentos para proteger os profissionais de saúde e atender a crescente população contaminada. Vinte e três avióes americanos foram dirigidos à China para buscar toneladas desses produtos (EUA enviam..., 2020). Fabricantes chineses já informam ao mundo que a fila de espera para novos contratos vai até o final de junho. Na Europa, carregamentos de equipamentos hospitalares e medicamentos estão simplesmente sendo confiscados durante escalas no trânsito entre os países (Coronavírus..., 2020).

Em meio à crescente rivalidade entre as naçôes (Guerra mundial..., 2020), é urgente a perspectiva do acirramento da crise sanitária e humanitária no Brasil pela carência desses produtos - desde máscaras até respiradores (Guerra por máscaras..., 2020). O Sistema Único de Saúde (SUS), um dos maiores sistemas públicos de saúde do mundo, vê-se subitamente fragilizado porque o país não conta com uma base produtiva e tecnológica suficientemente diversificada.

O risco de a atual crise evoluir para patamares dramáticos na verdade relaciona-se menos à qualidade do sistema de saúde do Brasil do que à sua fragilidade tecnológica e produtiva. $\mathrm{O}$ aumento dessas fragilidades em diversos dos nossos segmentos econômicos compromete sobremaneira a capacidade do Brasil em responder a crises como a atual. ${ }^{3}$

1. Especialista em políticas públicas e gestão governamental na Diretoria de Estudos e Políticas Setoriais de Inovação e Infraestrutura (Diset) do Ipea e editor deste Radar.

2. Especialista em políticas públicas e gestão governamental na Diretoria de Estudos e Relações Econômicas e Políticas Internacionais (Dinte) do Ipea.

3. Guilhoto e Morceiro (2019) destacam que o país passa por uma acelerada fragilização de suas cadeias produtivas - sem um correspondente aumento no esforço tecnológico e de inovação do restante do setor empresarial. 
O aumento das tensões comerciais e diplomáticas que vem marcando as primeiras décadas do século XXI apresentam-se como um complicador adicional para aquelas naçôes que dispóe de frágeis capacidades tecnológicas e produtivas autônomas. A crise, hoje, coloca-se no campo sanitário, mas o contexto de fundo, que é a nossa fragilidade produtiva e tecnológica, será novamente o ponto de estrangulamento da capacidade de resposta do Estado brasileiro quando novas crises irromperem.

Em particular, não se pode descartar novas epidemias globais - a Covid-19 já é a quarta em vinte anos -, muito menos crises ambientais, climáticas e energéticas, por exemplo. Qualquer que seja a natureza de uma eventual e provável crise futura, novamente serão as competências produtivas e tecnológicas que farão a diferença entre sucumbir, resistir ou mesmo transformá-la em oportunidade.

Assim, o presente artigo resgata o debate sobre essas políticas públicas como instrumentos de segurança nacional (em sentido amplo, como exposto a seguir) e estabilidade institucional.

\section{AÇÃO DO ESTADO ORIENTADA POR MISSÕES}

A crise do coronavírus trouxe uma das questóes mais controversas para o centro do debate: os limites da ação do Estado na economia.

Como a revista The Economist destacou recentemente (Rich..., 2020), a atuação emergencial do Estado como garantidor do sistema econômico e fornecedor de ajuda financeira e material para imensos contingentes populacionais passou a ser defensável para a grande parte dos economistas - ainda que o custo fiscal das medidas já anunciadas seja no mínimo 50\% maior que o da crise de 2008.

Todavia, não se pode perder de vista que a ação emergencial do Estado no caso brasileiro está seriamente comprometida pela ausência de uma base produtiva e tecnológica que deveria ter sido garantida por políticas públicas de ao menos uma década atrás. Ao não contar com a possibilidade de importaçóes na quantidade necessária, o país corre o risco de desabastecimento de insumos médicos e hospitalares.

Alianças institucionais pautadas por um pensamento autônomo e estratégico entre setor produtivo e Estado estão - ou ao menos estiveram - no centro do domínio científico e tecnológico dos Estados Unidos, da Europa e de alguns países asiáticos - sobretudo e crescentemente da China. Essas alianças institucionais se traduzem em políticas de desenvolvimento produtivo, tecnológico e de inovação.

Partindo da visão estratégica originária e concentrada no Estado, a celebração dessa aliança se dá não de forma reativa, pelas dificuldades que o setor produtivo tem para se desenvolver, mas sim pela instrumentalização do setor produtivo, por orientaçâo estratégica do Estado, para equacionar desafios nacionais.

Esse paradigma, referido na literatura como mission oriented (Mazzucato, 2017), ou seja, política de desenvolvimento produtivo, tecnológica e de inovação orientada por objetivos estratégicos, tem como virtude a capacidade de orientar o debate sobre a necessidade de tal tipo de política pública por dois motivos fundamentais:

- esclarece-se o alinhamento de objetivos e a razão da ação coordenada: enfrentar e resolver um determinado desafio nacional; e

- mitigam-se as possibilidades de captura institucional dos mecanismos de apoio financeiro/econômico do Estado ao setor produtivo; isso ocorre pela inversão da orientação: não é o Estado que se vê acionado pelo setor empresarial, mas justamente o contrário.

Vale apontar que um ponto controverso em debates sobre políticas de desenvolvimento produtivo, tecnológica e de inovação é o da determinação de quais setores econômicos devem ser priorizados. É sem dúvida justificada a cautela. Entretanto, as missóes aqui referidas decorrem de atividades essenciais para o próprio funcionamento do 
Estado, ou de assuntos de grande repercussão para o conjunto da sociedade. Assim, são as próprias funções do Estado que condicionam a pauta de desafios a serem superados, e não a escolha de setores econômicos a serem priorizados.

\section{O PAPEL DO ESTADO NA DEFINIÇÃO DAS AGENDAS}

Originalmente, a ideia de políticas mission oriented foi construída em contraposição à de políticas innovation oriented. Aqui, as denominaçôes são de pouca utilidade, haja vista que países democráticos, como os Estados Unidos e a França, inovam essencialmente a partir de grandes programas de longo prazo que trazem mais ou menos explicitamente missóes inscritas. O ponto essencial é que, em sistemas dominados por políticas do segundo tipo, a primazia em conduzir o papel do Estado nos sistemas de inovaçáo cabe à interação entre o setor produtivo e a academia através do sistema político. ${ }^{4}$

O modelo de política de inovação consagrado nos países da Organização para a Cooperação e Desenvolvimento Econômico (OCDE), e no qual o Brasil tem se espelhado nas últimas décadas, ${ }^{5}$ do tipo innovation oriented traz a hipótese de que interaçóes políticas abertas e transparentes resultam em benefícios para o conjunto da sociedade. Contudo, pode-se argumentar que nesse modelo o Estado participa de fato como um mero catalizador da interação entre o empresariado e a comunidade acadêmica, apenas ofertando instrumentos de apoio financeiro/econômico. Essa é a forma que tem sido adotada no Brasil.

No entanto, os sistemas de representação política tornam-se um veículo pelo qual as comunidades científicas e o sistema produtivo interferem recorrentemente na definição das agendas de pesquisa e na construção dos instrumentos públicos de apoio à pesquisa e inovação. Nesse contexto, é elevada a possibilidade de os instrumentos do Estado serem manobrados em favor de grupos de interesse pelo fenômeno da captura institucional. Isso inviabiliza a consolidação de perspectivas de longo prazo, que são essenciais para políticas de inovação e tecnológica minimamente ambiciosas.

Em que pese a importância de um sistema que permita uma concertação de agendas de pesquisa e inovação entre empresas e academia para a criação de um fluxo de geração de valor no mercado, não se pode ignorar que a liderança estratégica do Estado é essencial para a geração de soluções tecnológicas e inovadoras para questôes de segurança nacional.

Em trabalho recente, Mark Zachary Taylor estabelece que, fundamentalmente, o ponto-chave é a própria suspensão da interferência política nas decisões de Estado. Em outras palavras: o que torna alguns países mais tecnologicamente potentes que outros é a capacidade de instituir políticas "de segurança nacional” - segurança lato sensu, abrangendo para além da defesa nacional, a energia, a alimentação e a saúde. Outros autores, como Laura Weiss (2014), Meredith Woo (1998) e Richard Samuels (1994), adotam posiçóes semelhantes ao investigar as políticas públicas que países asiáticos vêm implementando e que têm os conduzido ao posto de potências produtivas e tecnológicas.

Esses autores enfatizam que o desenvolvimento produtivo e tecnológico a partir de "razóes de Estado" (Bobbio, 1983) não é mera retórica. O jogo de interesses políticos é um dado da realidade, mesmo em países como a China de hoje ou a Coreia dos anos 1970 e 1980. Isso é um fato inescapável e relevante na definição de

4. Conforme Taylor (2016). A referência a Olson (1996) ajuda a elucidar o ceticismo de Taylor com a reiterada importância do design institucional para a efetividade das políticas de desenvolvimento tecnológico, abrigando um ponto comumente caro aos economistas neoclássicos, do risco de captura em políticas industriais de corte vertical. Observe-se que, sem deixar de concordar com Taylor, destacamos como aspecto tão ou mais importante a dificuldade de se planejar e executar políticas tecnológicas minimamente ousadas, que demandam prazos muito superiores à vigência de um governo ou legislatura.

5. Para entender melhor a experiência brasileira das últimas duas décadas, ver De Negri e Rauen (2018) e De Negri, Rauen e Squeff (2018). 
prioridades e na forma institucional concreta com que as missóes são desdobradas em qualquer sistema político de qualquer nação.

Contudo, em alguns países, a percepção é de que a segurança nacional é imperativa - novamente, segurança lato sensu - e isso traz para o Estado o protagonismo na definição daquilo que é crucial não apenas para sua preservação, mas também para o bem-estar da população a longo prazo.

Obviamente, não se trata aqui de propugnar, para o caso brasileiro, um retorno a modelos do passado que propunham a autarquização. Trata-se de observar que a rejeição completa à ideia de que o Estado possa orientar uma autonomia produtiva e tecnológica em setores estratégicos reduziu o dinamismo tecnológico do país, aumentando sua fragilidade econômica e institucional. Claramente, o que temos praticado no Brasil contrasta com o que realizaram os países do leste asiático.

\section{CONCLUSÃO}

A pandemia de Covid-19 pode representar o momento para reiniciarmos uma discussão sobre o papel de políticas de desenvolvimento produtivo, tecnológico e de inovação para a segurança do Estado brasileiro. O caso atual é notório: a fragilidade da base produtiva e tecnológica nacional coloca em risco a efetividade do nosso sistema de saúde. Ao que tudo indica, situaçóes semelhantes seriam encontradas, mutatis mutandis, em outros complexos produtivos de grande relevância para a segurança nacional.

Assim, torna-se necessário compreendermos que há ao menos um punhado de grandes políticas públicas para as quais é preciso garantir a autonomia tecnológica e produtiva necessárias a seu atendimento. Depender quase integralmente de cadeias globais de suprimento pode comprometer a capacidade de oferecer condiçôes mínimas à população, como ilustra o caso atual.

Embora esse texto não ofereça soluçóes para o problema dessa pandemia, sugere-se que a construção de capacidade produtiva, tecnológica e inovadora orientadas por missóes e demandas de Estado aumentaria a capacidade do país em responder mais efetivamente a outras crises que possam nos acometer - e cuja probabilidade vem se elevando continuamente antes mesmo da atual crise. ${ }^{6}$

Se boa parte da literatura que explica os reiterados sucessos asiáticos estiver correta, ganharemos não apenas em incrementar nossa segurança sanitária, mas também em dar peso e acelerar nosso claudicante progresso tecnológico.

\section{REFERÊNCIAS}

ALLEN, J. et al. How the World Will Look After the Coronavirus Pandemic. Foreignpolicy.com, 20 March 2020. Disponível em: <https://bit.ly/2Vb2m34>.

BOBBIO, N. et al. Razão de Estado. Dicionário de política. Brasília: Editora da UnB, 1983.

CORONAVÍRUS: EUA são acusados de pirataria e desvio de equipamentos que iriam para Alemanha, França e Brasil. G1 mundo, 4 de abril de 2020. Disponível em: <https://glo.bo/2yVLMeB.

DE NEGRI, F.; RAUEN, A. Innovation policies in Brazil during the 2000s: the need for new paths. Brasília: Ipea, 2018.

DE NEGRI, F.; RAUEN, A.; SQUEFF, F. H. S. Ciência, inovação e produtividade: por uma nova geraçáo de políticas públicas. In: DE NEGRI, J.; ARAÚJO, B.; BACELETTE, R. (Orgs.). Desafios da Naçáo: artigos de apoio. Brasília: Ipea, 2018. 
EUA ENVIAM avióes cargueiros e limpam estoque de equipamentos médicos da China. Poder 360, 1 de abril de 2020. Disponível em: <https://bit.ly/2V6Fqlp>.

GUERRA MUNDIAL por equipamentos contra vírus vai afetar as naçóes, diz militares. Estadáo, 6 de abril de 2020. Disponível em: $<$ https://bit.ly/3elRxmk

GUERRA POR MÁSCARAS e respiradores reforça importância da indústria nacional Folha de S.Paulo, 7 de abril de 2020. Disponível em: <https://bit.ly/34BO4eI>.

GUILHOTO, P. R.; MORCEIRO, P. Penetração dos insumos importados na indústria brasileira. São Paulo: IEDI, 2019. MAZZUCATO, M. Mission-oriented innovation policy: challenges and opportunities, UCL Institute for Innovation and Public Purpose (IIPP), 2017. (Working Paper Series, n. 1).

OLSON, M. A lógica da ação coletiva. São Paulo: Edusp, 1996.

RICH countries try radical economic policies to counter Covid-19. The Economist, March 26th Edition.

SAMUELS, R. Rich nation strong army: national security and the technological transformation of Japan. Cornell: Cornell University Press, 1994.

TAYLOR, M. Z. The politics of innovation: why some countries are better than others at science and technology. Oxford, 2016.

WEISS, L. America Inc.? Innovation and enterprise in the national security state. Cornell: Cornell University Press, 2014.

WOO-CUMMINGS, M. J-E. National Security and the Rise of the Developmental State in Korea and Taiwan. In: ROWEN, H.S. Behind East Asian Growth: the political and social foundations of prosperity. London: Routledge, 1998. 
